\title{
High prevalence of overweight and obesity among a representative sample of Puerto Rican children
}

\author{
Augusto R Elías-Boneta ${ }^{*}$, Milagros J Toro ${ }^{1}$, Omar Garcia $^{1+}$, Roxana Torres ${ }^{2+}$ and Cristina Palacios ${ }^{2}$
}

\begin{abstract}
Background: The prevalence of childhood overweight and obesity has become a public health problem worldwide. The objectives of the study were: 1) to establish the BMI prevalence in 12-year olds residing in Puerto Rico, and 2) to determine BMI differences by sex, public-private school type, and geographic regions.

Methods: Data was obtained from an island-wide probabilistic stratified sample of 1,582 twelve-year-olds (53\% girls and $47 \%$ boys). The BMI was determined using the National Health and Nutrition Examination Survey procedures. Children were categorized as underweight, healthy weight, overweight or obese using the Center for Disease Control and Prevention's age and gender specific growth charts. A logistic regression model was used to estimate BMI category prevalence. Odds ratios were calculated using a multinomial regression.
\end{abstract}

Results: In this study, $18.8 \%$ of the children were overweight and $24.3 \%$ were obese. A higher prevalence of obesity was observed in boys as compared to girls, $28.2 \%$ vs. $20.2 \%$, respectively. The estimated prevalence of overweight and obesity in children from public schools was lower than for those from private schools. After adjusting for type of school and region, boys had a significantly higher risk of being obese (64\%) as compared to girls. In public schools, boys had a lower prevalence of being overweight while girls had a higher prevalence compared to children attending private schools. Girls attending private schools had a higher obesity prevalence (27.8\%) compared to girls from public schools (19.8\%). The prevalence of underweight (2.7\%) is slightly lower than in the United States.

Conclusions: The prevalence of overweight and obesity of 12-year-olds residing in PR was 18.8\% and 24.3\%, respectively; higher than in the U.S. (by groups). Boys were at higher risk of obesity than girls. There is an urgent need to implement public health policies/programs to reduce the prevalence of overweight and obesity in children in PR.

Keywords: Overweight, Obesity, Prevalence, Children, Puerto Rico

\section{Background}

Childhood obesity is a serious public health problem worldwide [1-3] affecting low and middle income families [4]. During childhood and adolescence, being obese or overweight may lead to physical, psychological, and social health problems [5-11]. These health conditions may persist through adulthood [12], contributing to a significantly lower health-related quality of life [13]. Moreover, obesity/overweight associated-health conditions are related to the primary causes of mortality worldwide [14-16]. The burden of cardiovascular disease (CVD) for Puerto Ricans is substantial. Cardiometabolic

\footnotetext{
* Correspondence: augusto.elias@upr.edu

${ }^{\dagger}$ Equal contributors

'School of Dental Medicine, Medical Sciences Campus, University of Puerto Rico, Rio Piedras, Puerto Rico

Full list of author information is available at the end of the article
}

risk refers to the probability of having diabetes, heart disease or stroke [17]. For U.S. residing Puerto Ricans approximately $18 \%$ of the adults had diabetes, $28 \%$ hypertension, and $45 \%$ hypercholesterolemia, as examples of metabolic conditions [18]. For Puerto Ricans residing in the island, $13.5 \%$ self-reported diabetes, $37 \%$ had hypertension, and $38 \%$ hypercholesterolemia, among other CVD factors [19].

The worldwide prevalence of childhood overweight and obesity increased 10\% between 1990 and 2010 [20]. During the last 30 years, childhood obesity in the US has more than doubled and has quadrupled in adolescents $[21,22]$. The 2011-2012 National Health and Nutrition Examination Survey (NHANES) [22] states that $34.5 \%$ of the $12-19$ year-olds were obese or overweight and $20.5 \%$ were obese. In this report, obesity was higher 
among non-Hispanic black and Hispanic children as well as adolescents compared to non-Hispanic white children. Obesity rates of Puerto Rican children in mainland US and in PR are among the highest (24-36\%) when compared to other racial/ethnic groups [23]. An islandwide study conducted among 3,079 second graders established the prevalence of at risk of overweight at $16 \%$ and of overweight at 26\% [24]; these categories are currently termed overweight and obese, respectively [25]. In another investigation, the combined self-reported prevalence of overweight and obesity in 10-19 year-olds in PR was $34.9 \%$ while in $10-14$ year-olds was $52.3 \%$ [26]. Moreover, a study of 250 elementary school children in PR revealed that $26.8 \%$ were obese and $11.3 \%$ were overweight [27]. These previous studies employed convenient samples of limited size in specific communities except the study conducted among second graders [24], which was published as a government report in Spanish.

In the U.S., Healthy People 2020 established targets to guide the health promotion and disease prevention efforts [28] and to reduce obesity in children and adolescents [29]. In PR, the only island-wide study, on childhood obesity was conducted in 2005 [24]; therefore, no ongoing surveillance program exist posing a challenge to monitor changes and control these conditions. The objectives of the study are: 1 ) to establish the BMI prevalence in 12-year olds residing in Puerto Rico, and 2) to determine BMI differences by sex, publicprivate school type, and geographic regions.

\section{Methods}

\section{Study and sample design}

The present study was an ancillary, island-wide crosssectional study designed to examine oral health status of 12 -year-olds residing in PR. Although boys and girls aged 12 are at a different pubertal stage, the World Health Organization recommends this age group to establish international oral health comparisons [30], which was the primary goal of this investigation. The sample design allows the inference for the population of all 12 year-olds enrolled in school during the study period (November 2010 to May 2011). According to the PR General Council on Education and the Department of Education, there were 51,376 (40,081 in public and 11,295 in private schools) 12-year-olds enrolled in school. Public and private schools, serving fifth to seven graders in PR during the study period, were used as the target sample.

\section{Sample selection}

A probabilistic sample of 133 schools was selected from a total of 1,843 schools (1,343 public and 500 private schools). The sample is proportional to enrollment size, and stratified by the 11 health administrative regions (as determined by "Reforma", the PR government's health insurance program in 1997) [31], type of school (public and private), and gender. Ten boys and ten girls were randomly selected from each school using the official student lists provided by the school's administration. The required sample size was 2,600 children. A total of 1,734 children were contacted and invited to participate, however, some of the selected schools were inactive and others had merged. One hundred-fifty two (152) children were excluded due to school absences and failure to obtain their parent's written consent.

\section{Inclusion/exclusion criteria}

The inclusion criteria: 12-years-of-age at the time of recruitment; healthy (no history of medical problems that contraindicate their participation in the study). The exclusion criteria: not competent to give their consent or unable to withstand a clinical procedure.

Parents or guardians signed a written informed consent and children provided written assent approved by the Institutional Review Board of the Medical Sciences Campus of the University of PR.

\section{Socio-demographics and anthropometric measurements}

Socio-demographic data was obtained from a self-reported medical history questionnaire answered by the legal guardian. In PR, public/private school attendance may be considered a surrogate measure for the family's socioeconomic status [31], which was confirmed in a subset sample [32]. In addition, it has been reported that over $86 \%$ of the students attending public school in PR are socio-economically disadvantaged [33], thus the type of school attended was interpreted as a proxy of the participant's socio-economic status. Trained staff measured children's height and weight following the NHANES III procedures [34]. Height was measured in meters using a portable stadiometer (Seca Corporation, Hanover, MD) and weight was measured in kilograms using a Body Composition Analyzer (TBF-310A, Tanita Corporation of America, Arlington Heighs, IL), calibrated prior to each use. These anthropometric measurements were made while the children were wearing their uniforms (without socks, shoes, and accessories). Body Mass Index (BMI) was calculated using the following formula: weight $(\mathrm{kg}) /$ height $(\mathrm{m})^{2}$.

Children were categorized as underweight, healthy weight, overweight, or obese using the Center for Disease Control and Prevention's age and gender specific growth charts [35], as follows: underweight (BMI $<5^{\text {th }}$ percentile), healthy weight (BMI between the $5^{\text {th }}$ percentile and $<85^{\text {th }}$ percentile), overweight (BMI between $>85^{\text {th }}$ percentile and $<95^{\text {th }}$ percentile), and obese (BMI $>95^{\text {th }}$ percentile) for children of the same age and gender [36]. 


\section{Statistical analysis}

The overall estimated prevalence and prevalence odd ratios $(P O R)$ for the different BMI categories were calculated. The overall estimated prevalences were also calculated by socio-demographic variables (gender and type of school) and their interactions for each weight category were estimated using a logistic regression model [37] as follows:

$$
P_{i}=\frac{1}{1+e^{\left(B o+B_{i} X_{i} \pm 1.9 S E\right)}}
$$

describes the estimator of the weight category;

$\beta_{0}$ is the model intercept, $x_{i}$ is a socio-demographical variable;

and $\beta_{1}$ is a change for each category.

In addition, a descriptive analysis by region was conducted using the 11 health administrative regions.

POR were calculated using a multinomial logistic regression to evaluate association between the weight category (overweight or obese) and socio-demographic variables (gender, type of school, and school zone). The base outcome for these models was normal weight. The 11 health regions were collapsed into 3 zones for the POR calculation based on the diet intake differences among these zones [32]: Coastal, Metropolitan, and Central Mountain. A robust variance estimator was used to determine the standard errors of the prevalence parameters due to the school effect. All statistical analyses used robust variance estimators to determine the standard errors of the prevalence parameters for intraclass correlation within school. Weights were assigned to each student by using the inverse of the probability of selection of the sampling design. All statistical analyses were conducted by incorporating the sampling weight to obtain unbiased estimates from the sampling design, using the statistical package Stata (Version 12.0, College Station, TX, USA). A probability value of 0.05 was considered statistically significant.

\section{Results}

A total of one thousand five hundred and eighty two $(\mathrm{n}=1,582)$ subjects were evaluated between November 2010 and May 2011. The distribution of the demographic characteristics of gender and type of school attended were as follows: $53 \%$ females, $47 \%$ males; $77.2 \%$ public schools, $22.8 \%$ private schools. The distribution in relation to the school's region was: North (10.5\%), Northwest (4.9\%), Northeast (6.0\%), East (8.2\%), Southeast (9.0\%), Southwest (5.2\%), Ponce (4.3\%), West (4.9\%), Metro area (22.8\%), San Juan (10.3\%) and Mountain (14.0\%). By zones, the distribution was: Coast $(\mathrm{n}=837 ; 52.9 \%)$, Metropolitan $(\mathrm{n}=523$; 33.1\%) and Central Mountain $(n=222 ; 14.0 \%)$.
The estimated prevalence and $95 \%$ confidence intervals (CI) for each BMI category are shown in Table 1. Overall, the prevalence of obesity was $24.3 \%$ (CI: $19.9 \%, 29.2 \%$ ) and for overweight it was $18.8 \%$ (CI: 16.4\%, 20.3\%). A higher prevalence of obesity was seen in boys $(28.2 \%, \mathrm{CI}$ : $18.7 \%$, $40.1 \%$ ) than in girls (20.2\%, CI: $19.5 \%, 29.2 \%)$. In terms of school type, children in public schools had a lower prevalence of overweight (18.6\%, CI: $15.4 \%, 22.4 \%)$ and obesity (24.0\%, CI: $19.5 \%, 29.2 \%)$, when compared to children in private schools (overweight 21.2\%, CI: $16.4 \%, 27.1 \%$; obese $28.2 \%$, CI: $18.7 \%, 40.1 \%)$.

Table 2 shows the estimated prevalence of overweight and obesity stratified by type of school and gender. In private schools, more boys were overweight $(26.6 \%$, CI: $15.3 \%, 38.1 \%)$ than in public schools $(17.9 \%, \mathrm{CI}: 13.9 \%$. $21.9 \%)$. Girls from private schools had a lower prevalence of overweight $(15.1 \%, \mathrm{CI}: 8.97 \%, 21.3 \%)$ than those in public schools $(19.2 \%, \mathrm{CI}: 14.8 \%, 23.7 \%)$; while obesity prevalence in girls from private schools $(27.8 \%, \mathrm{CI}$ : $15.9 \%, 39.7 \%)$ was higher compared to those attending public schools (19.8\%, CI: 15.4\%, 24.3\%). This difference was not observed in boys.

Boys were at a significantly higher risk $(\mathrm{POR}$ weighted $=1.64$, CI: $1.18,2.35)$ of being obese compared to girls, after adjusting for type of school and region. No other statistical differences were observed (Table 3).

Children in the East, Northeast and Southwest regions had the highest estimated prevalence of overweight $(\geq 19.5 \%)$, while the Southeast and Northwest regions had the lowest $(14.1 \%$ and $14.3 \%$, respectively). The highest obesity prevalence was found in the Northeast region (33.7\%), followed by Northwest region (25.9\%), and Ponce (25.0\%). The lowest was observed in the Mountain and Southwest regions (19.4\% and 19.5\%, respectively).

\section{Discussion}

The aim of this study were to establish the BMI prevalence in 12-year olds residing in Puerto Rico, and to determine BMI differences by sex, public-private school type, and geographic regions.. We found that the overweight prevalence was $18.8 \%$, which is higher than those reported in prior studies in Puerto Rican children aged 7 years (16.2\%) [24] and 9-10 years (11.3\%) [27]. The overall prevalence of obesity was $24.3 \%$, which is slightly lower than the prevalence reported in the aforementioned studies in PR (25.7\% and 26.8\%) [24] [27]. The obesity prevalence in PR, as presented by this study, is higher than the overall prevalence in U. S. for 12-19year-olds (20.5\%) and higher when stratified by race/ ethnicity (whites 19.6\%, non-Hispanic blacks $22.1 \%$, and Hispanics 22.6\%) [38]. Overweight prevalence in the U.S. was presented together with obesity data, precluding its comparison [38]. The prevalence of underweight in this study (2.7\%) is slightly lower than in the US (3.6\%) [39]. 
Table 1 Estimated Prevalence and 95\% Cl of Underweight, Healthy Weight, Overweight, and Obesity by Gender and School Type

\begin{tabular}{|c|c|c|c|c|c|c|c|c|c|}
\hline & & \multicolumn{2}{|l|}{ Underweight } & \multicolumn{2}{|l|}{ Normal weight } & \multicolumn{2}{|l|}{ Overweight } & \multicolumn{2}{|l|}{ Obese } \\
\hline & & Weighted $^{1}$ & Unweighted & Weighted $^{1}$ & Unweighted & Weighted $^{1}$ & Unweighted & Weighted $^{1}$ & Unweighted \\
\hline \multirow{2}{*}{\multicolumn{2}{|c|}{ Overall $n=1,582$}} & $2.7 \%(1.8,4.1)^{2}$ & $3.0 \%(2.3,4.0)$ & $54.3 \%(50.2,58.3)$ & $55.5 \%(53.0,57.9)$ & $18.8 \%(16.4,20.3)$ & $18.3 \%(16.4,20.3)$ & $24.3 \%(19.9,29.2)$ & $23.2 \%(21.2,25.3)$ \\
\hline & & $n=48$ & & $\mathrm{n}=878$ & & $n=289$ & & $n=367$ & \\
\hline \multirow[t]{4}{*}{ Gender } & Boys $n=744$ & $2.7 \%(1.7,4.4)$ & $3.9 \%(2.7,5.6)$ & $50.1 \%(44.2,56.0)$ & $52.7 \%(49.1,53.7)$ & $18.5 \%(14.9,22.6)$ & $17.3 \%(14.8,20.2)$ & $28.2 \%(18.7,40.1)$ & $26.1 \%(23.1,29.4)$ \\
\hline & & $n=29$ & & $n=392$ & & $n=129$ & & $n=194$ & \\
\hline & Girls $n=\mathbf{8 3 8}$ & $2.7 \%(1.6,4.4)$ & $2.3 \%(1.5,3.5)$ & $58.1 \%(53.1,62.9)$ & $58.0 \%(54.6,61.3)$ & $19.0 \%(14.6,22.3)$ & $19.1 \%(16.4,21.8)$ & $20.2 \%(19.5,29.2)$ & $20.6 \%(18.0,23.5)$ \\
\hline & & $n=19$ & & $n=486$ & & $n=160$ & & $n=173$ & \\
\hline \multirow[t]{4}{*}{ School Type } & Public $\mathbf{n}=\mathbf{1 , 2 2 1}$ & $2.7 \%(1.8,4.2)$ & $3.3 \%(2.4,4.4)$ & $54.6 \%(50.3,58.8)$ & $56.4 \%(53.5,59.1)$ & $18.6 \%(15.4,22.4)$ & $18.6 \%(15.4,22.4)$ & $24.0 \%(19.5,29.2)$ & $22.4 \%(20.1,24.8)$ \\
\hline & & $n=40$ & & $n=688$ & & $n=220$ & & $n=273$ & \\
\hline & Private $\mathbf{n}=\mathbf{3 6 1}$ & $2.1 \%(1.0,4.3)$ & $2.2 \%(1.1,4.4)$ & $48.5 \%(35.9,61.3)$ & $52.6 \%(47.5,57.7)$ & $21.2 \%(16.4,27.1)$ & $19.1 \%(15.4,23.5)$ & $28.2 \%(18.7,40.1)$ & $26.0 \%(21.8,30.8)$ \\
\hline & & $n=8$ & & $n=190$ & & $n=69$ & & $n=94$ & \\
\hline
\end{tabular}

${ }^{1}$ weighted by the inverse probability $(1 / p)$ of the selection.

${ }^{2} 95 \%$ Confidence Interval (Cl). 
Table 2 Estimated Prevalence of Underweight, Healthy Weight, Overweight, and Obese by Gender and School Type

\begin{tabular}{|c|c|c|c|c|c|}
\hline \multirow[t]{3}{*}{ BMI Categories } & & \multicolumn{4}{|l|}{ School type } \\
\hline & & \multicolumn{2}{|l|}{ Public $(n=1,221)$} & \multicolumn{2}{|l|}{ Private $(n=361)$} \\
\hline & & Weighted $^{1}$ & Unweighted & Weighted $^{1}$ & Unweighted \\
\hline \multirow[t]{4}{*}{ Underweight $\mathbf{n}=\mathbf{4 8}$} & Boys $\mathbf{n}=\mathbf{2 9}$ & $2.8 \%(1.37,4.20)^{2}$ & $4.4 \%(2.89,5.96)$ & $2.0 \%(0.035,4.01)$ & $2.2 \%(0.32,4.15)$ \\
\hline & & $\mathrm{n}=\mathbf{2 5}$ & & $\mathrm{n}=4$ & \\
\hline & Girls $n=19$ & $2.7 \%(1.27,4.11)$ & $2.3 \%(1.23,3.33)$ & $2.2 \%(-0.17,4.55)$ & $2.2 \%(1.72,4.22)$ \\
\hline & & $n=15$ & & $\mathrm{n}=4$ & \\
\hline \multirow[t]{4}{*}{ Healthy Weight $\mathbf{n}=\mathbf{8 7 8}$} & Boys $\mathbf{n}=\mathbf{3 9 2}$ & $50.6 \%(44.38,56.87)$ & $53.6 \%(49.20,58.05)$ & $42.8 \%(24.84,60.72)$ & $49.7 \%(41.17,58.27)$ \\
\hline & & $\mathrm{n}=303$ & & $n=89$ & \\
\hline & Girls $\mathbf{n}=\mathbf{4 8 6}$ & $58.2 \%(53.04,63.44)$ & $58.7 \%(54.62,62.76)$ & $54.9 \%(42.17,67.66)$ & $55.5 \%(48.47,62.52)$ \\
\hline & & $\mathrm{n}=385$ & & $\mathrm{n}=101$ & \\
\hline \multirow[t]{4}{*}{ Overweight $\mathbf{n}=\mathbf{2 8 9}$} & Boys $n=129$ & $17.9 \%(13.94,21.92)$ & $16.4 \%(13.5,19.34)$ & $26.7 \%(15.25,38.07)$ & $20.1 \%(13.93,26.29)$ \\
\hline & & $\mathrm{n}=93$ & & $\mathrm{n}=36$ & \\
\hline & Girls $\mathbf{n}=160$ & $19.2 \%(14.75,23.74)$ & $19.4 \%(16.45,22.29)$ & $15.1 \%(8.97,21.27)$ & $18.1 \%(13.34,22.92)$ \\
\hline & & $n=127$ & & $\mathrm{n}=33$ & \\
\hline \multirow[t]{4}{*}{ Obesity $\mathbf{n}=\mathbf{3 6 7}$} & Boys $n=194$ & $28.7 \%(21.76,35.57)$ & $25.5 \%(21,7929.18)$ & $28.5 \%(16.63,40.44)$ & $27.9 \%(20.11,35.75)$ \\
\hline & & $n=144$ & & $\mathrm{n}=50$ & \\
\hline & Girls $\mathbf{n}=173$ & $19.8 \%(15.35,24.30)$ & $19.7 \%(16.13,23.01)$ & $27.8 \%(15.87,39.68)$ & $24.2 \%(17.96,30.39)$ \\
\hline & & $n=129$ & & $n=44$ & \\
\hline
\end{tabular}

${ }^{1}$ weighted by the inverse probability $(1 / p)$ of the selection.

${ }^{2} 95 \%$ Confidence Interval.

The current study portrayed boys with a higher prevalence of obesity but similar prevalence of overweight when compared to girls while boys were at significantly higher risk of being obese compared to girls. A previous study in PR found that boys had a higher prevalence of obesity compared to girls $(26.9 \%$ vs. $24.5 \%)$; however, the overweight prevalence for girls was higher than for boys $(17.4 \%$ vs. 14.8\%) [24]. This finding is similar to a recent study in 436 Puerto Ricans aged 10-19 years [26], whereas it was reported that females were $50 \%$ less likely than males to be overweight or obese. The current study's results are consistent with US national data from NHANES 2009-10, where male children and adolescents from all racial/ethnic groups had higher obesity prevalence compared to females [40].
The obesity prevalence data from NHANES 201112 [22] showed no differences in gender when all races/Hispanic origin groups were considered. The exception was between Hispanics and non-Hispanic Asian boys, who had higher obesity prevalence when compared to girls; however, these differences were not statistically significant. Worldwide data indicates that adolescent boys have higher prevalence of obesity in almost all nations and higher prevalence of overweight in almost half of the countries compared to girls [3]. Weight differences between boys and girls may be related to awareness of weight control and to body image issues that may develop in preadolescence [41].

Table 3 Weighted Prevalence Odd-ratios (POR weighted) for obese or overweight vs. healthy weight and socio-demographic variables $(n=1534)^{1}$

\begin{tabular}{|c|c|c|c|c|c|}
\hline & & \multicolumn{2}{|l|}{ Overweight $^{2}$} & \multicolumn{2}{|l|}{ Obese $^{2}$} \\
\hline & & Crude & Adjusted $^{3}$ & Crude & Adjusted $^{3}$ \\
\hline Gender & Boys $^{4}$ & $1.12(0.80,1.58)$ & $1.11(0.79,1.57)$ & $1.64(1.18,2.29)$ & $1.66(1.17,2.35)$ \\
\hline School type & Public $^{5}$ & $0.78(0.47,1.30)$ & $0.81(0.50,1.32)$ & $0.76(0.38,1.50)$ & $0.72(0.37,1.42)$ \\
\hline \multirow[t]{2}{*}{ Zone } & Metro $^{6}$ & $1.23(0.604,2.51)$ & $1.20(0.58,2.46)$ & $0.74(0.33,1.65)$ & $0.65(0.31,1.37)$ \\
\hline & Coast $^{6}$ & $1.20(0.56,2.57)$ & $1.18(0.55,2.56)$ & $0.67(0.32,1.39)$ & $0.69(0.30,1.58)$ \\
\hline
\end{tabular}

${ }^{1}$ Underweight Children were excluded of the multinomial logistic regression models.

${ }^{2}$ Reference outcome (normal).

${ }^{3}$ Adjusted by gender, type of school, and region.

${ }^{4}$ Reference category: girls.

${ }^{5}$ Reference category: private school.

${ }^{6}$ Reference category: Center/Mountain Zone. 
Regarding the type of school attended, children from private schools had a higher prevalence of overweight and obesity than those attending public schools. The results are consistent with those of the 2005 island-wide study [24] where children attending private schools had a higher BMI than those attending public school. It is possible that children who attend private school, a surrogate (indication?) to higher socioeconomic status in $\mathrm{PR}$, have higher purchasing power to consume sweets, snacks, and fast foods more often. These findings may be also attributed to the existence of the National School Lunch Program (NSLP) in the public school system, which is not available in most private schools. It has been reported that children participating in the NSLP have lower prevalence of overweight and obesity than non-participating children [42]. NSLP provides nutritionally balanced meals for lunch, which could be beneficial in reducing the risk of overweight and obesity.

Overall, we observed a higher risk of obesity in boys as compared to girls. When stratified by gender and type of school, the study suggests a high prevalence of obesity in boys in both public and private schools; however, girls from private schools had higher obesity prevalence than those in public schools. In contrast, the percentage of overweight girls attending public school was higher but no significantly different than those attending private school. Similarly, the study conducted in Cayey, PR, reported a higher prevalence of obese/overweight in girls from private schools compared to girls from public schools [27]. Another study in children and adolescents attending public schools in the San Juan Metropolitan Area reported that girls had a better diet compared to boys due to their higher participation rate in the NSLP [43]. Therefore, participation in the NSLP program provides an alternative explanation for the weight differences between boys and girls in PR.

A recent study conducted in the San Juan Metropolitan area found that girls had significantly higher scores for whole fruits and vegetables than boys [44]. In addition, overweight/obese children had a significantly lower availability of unhealthy foods at home, higher access to home recreational/sport facilities, lower use of school recreational/sport facilities, but reduced participation in school breakfast programs (SBP). The authors concluded that all participants had either poor diet or a diet that was not adequate [45]. Although the diet data was obtained by interviews with trained nutritionist, the availability and access to healthy or unhealthy foods and to sports and recreation was obtained through self-reported nutrition questionnaires. More research is needed to assess the factors associated with overweight/ obesity and to assess the contribution of the SBP, NSLP, and other dietary habits on caloric intake and meal quality offered in private schools and health regions.
Our study revealed that the highest obesity prevalence was found in the Northeast, Northwest, and Ponce regions of PR, and the lowest prevalence in the Mountain and Southwest regions. Our findings are in partial agreement with an island-wide study conducted in a representative sample of second graders. In this study, the highest obesity prevalence was found in the municipalities located in the Eastern and Northern regions; the lowest prevalence was observed in the Metropolitan area [24]. Body weight differences among regions may be due to local environmental factors such as the availability of healthy and unhealthy foods and food outlets as well as the accessibility of recreational/sports facilities and physical activity programs at home and school [46-48]. Unfortunately, the difference in the number of health regions and their geographical boundaries prevent an in-depth comparison between the two studies.

According to the 2010-11 U.S. Census, $45.6 \%$ of Puerto Ricans households fall below the poverty level [49]. Health inequalities exist and persist between Puerto Ricans residing in the island and US citizens in the mainland. For example, even though the prevalence of obesity/obesityrelated diseases is higher in PR [50], the island does not have an ongoing surveillance program to project 2020 obesity trends in school-age children. Considering NHANES historical trends in obesity (1971-2008), US children are projected in 2020 to be $1.8 \mathrm{~kg}$ heavier than a child in 2007-2008, and adolescents to be $2.7 \mathrm{~kg}$ heavier than adolescents during this period. It has been estimated that a child should reduce his/her caloric intake by $164-286 \mathrm{kcal} /$ day, depending on their raceethnicity, to achieve the goals of Healthy People 2020 [51]. Currently, the daily caloric intake required to meet these goals cannot be determined in PR. To define the appropriate reduction in caloric intake for Puerto Rican children, it is necessary to determine obesity trends and future projections. Risk factors including diet, physical activity, and other behavioral, social and physical environmental health determinants need to be investigated to better understand the complexity of obesity in Puerto Rican children to reduce this gap. Further investigation is needed to determine the social, physical and environmental factors related to this public health problem, allowing designing suitable policies and programs to reduce the prevalence of overweight and obesity.

One of the strengths of this study is the inclusion of a large and representative sample of 12 -year-olds residing in PR. The interviewers and personnel conducting the anthropometry were trained using standardized methods. One of the limitations in regards to obesity is that the sampling was designed to estimate oral health outcomes; in consequence, important risk factors including dietary/ snacking habits and physical activity of the child, as well as potential parental correlates, e.g., weight/obesity status 
were not investigated as study variables. However, with no contemporary anthropometric data on children in PR, island-wide, population-base BMI data is of importance for the public health community. Further investigation of these important obesity risk factors is required. When stratified by gender and type of school/region, some of the strata had limited number of subjects. Since BMI is not a good indicator of visceral obesity, future studies should include other anthropometric measurements including waist circumference, a simple and inexpensive method.

This island-wide study provides current data on the magnitude of the childhood overweight and obesity epidemic in PR. Our findings may contribute in mobilizing resources for the design of studies to identify successful policies and interventions.

\section{Conclusions}

The prevalence of overweight and obesity of 12-yearolds in PR was $18.8 \%$ and $24.3 \%$, respectively. These values are higher than those reported by NHANES in US children. Boys are at a higher risk of overweight/ obesity when compared to girls.

\section{Competing interests}

The authors declare that they have no competing interests.

\section{Authors' contributions}

ARE conceived of the study, participated in its design and coordination and gave the final approval of the version to be published. MJT participated in drafting the manuscript and revising it critically for intellectual content. OG, participated in the design of the study, performed the statistical analysis, and helped to draft the manuscript. RT helped to draft the manuscript. CP made substantial contribution to conception and design helped to draft and revise critically the manuscript. All authors have read and approved the final manuscript.

\section{Acknowledgements}

This study was partially supported by NIMHHD (1S21-MD001830), by NCR (2G12-RR003051), NIMHHD (8G12-MD007600) and Colgate- Palmolive (Caribbean) Inc. We thank Dr. Margarita Murillo (examiner), Dr. Luis Orraca (Project Director), and Angeliz Encarnación for their help in data collection. Also, we thank Dr. Carlos Toro for his help with the statistical analysis and Dr. Walter Psoter for critically revising the manuscript.

\section{Author details}

${ }^{1}$ School of Dental Medicine, Medical Sciences Campus, University of Puerto Rico, Rio Piedras, Puerto Rico. ${ }^{2}$ School of Public Health, Medical Sciences Campus, University of Puerto Rico, Rio Piedras, Puerto Rico.

Received: 8 September 2014 Accepted: 16 February 2015 Published online: 05 March 2015

\section{References}

1. Selassie M, Sinha AC. The epidemiology and aetiology of obesity: a global challenge. Best Pract Res Clin Anaesthesiol. 2011;25:1-9.

2. Karnik S, Kanekar A. Childhood obesity: a global public health crisis. Int J Prev Med. 2012;3:1-7.

3. Bibiloni MDM, Pons A, Tur JA. Prevalence of overweight and obesity in adolescents: a systematic review. ISRN Obes. 2013;2013:392747.

4. WHO. Global Strategy on Diet, Physical Activity and Health. Childhood overweight and obesity. http://www.who.int/dietphysicalactivity/childhood/en/

5. Van Kruijsdijk RCM, van der Wall E, Visseren FLJ. Obesity and cancer: the role of dysfunctional adipose tissue. Cancer Epidemiol Biomarkers Prev. 2009;18:2569-78.
6. Biro FM, Wien M. Childhood obesity and adult morbidities. Am J Clin Nutr. 2010;91:1499S-505S.

7. Nejat EJ, Polotsky AJ, Pal L. Predictors of chronic disease at midlife and beyond-the health risks of obesity. Maturitas. 2010;65:106-11.

8. Reilly JJ, Kelly J. Long-term impact of overweight and obesity in childhood and adolescence on morbidity and premature mortality in adulthood: systematic review. Int J Obes (Lond). 2011;35:891-8.

9. Erermis S, Cetin N, Tamar M, Bukusoglu N, Akdeniz F, Goksen D. Is obesity a risk factor for psychopathology among adolescents? Pediatr Int. 2004:46:296-301.

10. Abilés V, Rodríguez-Ruiz S, Abilés J, Mellado C, García A, Pérez de la Cruz A, et al. Psychological characteristics of morbidly obese candidates for bariatric surgery. Obes Surg. 2010;20:161-7.

11. Cromley T, Knatz S, Rockwell R, Neumark-Sztainer D, Story M, Boutelle K. Relationships between body satisfaction and psychological functioning and weight-related cognitions and behaviors in overweight adolescents. J Adolesc Health. 2012;50:651-3.

12. Togashi K, Masuda H, Rankinen T, Tanaka S, Bouchard C, Kamiya H. A 12-year follow-up study of treated obese children in Japan. Int J Obes Relat Metab Disord. 2002;26:770-7.

13. Schwimmer JB, Burwinkle TM, Varni JW. Health-related quality of life of severely obese children and adolescents. JAMA. 2003;289:1813-9.

14. Guh DP, Zhang W, Bansback N, Amarsi Z, Birmingham CL, Anis AH. The incidence of co-morbidities related to obesity and overweight: a systematic review and meta-analysis. BMC Public Health. 2009;9:88.

15. Borrell LN, Samuel L. Body mass index categories and mortality risk in US adults: the effect of overweight and obesity on advancing death. Am J Public Health. 2014;104:512-9.

16. Rodriguez Al, Geerman FPF. Puerto Rico Community Health Assessment: Secondary Data Analysis. http://soph.md.rcm.upr.edu/demo/images/DocSalud/DS_PRCHASecondaryDataAnalysisFinal_201212.pdf.

17. Papakonstantinou E, Lambadiari V, Dimitriadis G, Zampelas A. Metabolic syndrome and cardiometabolic risk factors. Curr Vasc Pharmacol. 2013;11:858-79.

18. Daviglus ML, Talavera GA, Avilés-Santa ML, Allison M, Cai J, Criqui MH, et al. Prevalence of major cardiovascular risk factors and cardiovascular diseases among Hispanic/Latino individuals of diverse backgrounds in the United States. JAMA. 2012;308:1775-84.

19. Puerto Rico Department of Health. Puerto Rico Chronic Disease Action Plan 2014-2020. http://www.iccpportal.org/sites/default/files/plans/Puerto\% 20Rico\%20Chronic\%20Disease\%20Action\%20Plan\%20English.pdf.

20. De Onis M, Blössner M, Borghi E. Global prevalence and trends of overweight and obesity among preschool children. Am J Clin Nutr. 2010;92:1257-64.

21. Centers for Disease Control and Prevention. Childhood Obesity Facts Prevalence of Childhood. Obesity in the United States, 2011-2012. 2014.

22. Ogden CL, Carroll MD, Kit BK, Flegal KM. Prevalence of childhood and adult obesity in the United States, 2011-2012. JAMA. 2014;311:806-14.

23. Acosta-Pérez E, Canino G, Ramírez R, Prelip M, Martin M, Ortega AN. Do Puerto Rican youth with asthma and obesity have higher odds for mental health disorders? Psychosomatics. 2012;53:162-71.

24. Pérez R, Duran G, Rullan MDC, Torres E, Rodriguez A CM. Estudio Para Estimar La Prevalencia de Sobrepeso En Niños de Segundo Grado de Las Escuelas de Puerto Rico. Departamento de Salud de Puerto Rico, San Juan; 2006.

25. Ogden, C L FK. Changes in the Terminology for Childhood Overweight and Obesity. National Health Statistics Reports; No 25. Hyattsville, MD: National Center for Health Statistics; 2010.

26. Garza JR, Pérez EA, Prelip M, McCarthy WJ, Feldman JM, Canino G, et al. Occurrence and correlates of overweight and obesity among island Puerto Rican youth. Ethn Dis. 2011;21:163-9.

27. Rivera-Soto WT, Rodríguez-Figueroa L, Calderón G. Prevalence of childhood obesity in a representative sample of elementary school children in Puerto Rico by socio-demographic characteristics, 2008. P R Health Sci J. 2010;29:357-63.

28. Healthy People 2020 [http://www.healthypeople.gov/2020/about/default.aspx]

29. Healthy People 2020. Objectives [http://www.healthypeople.gov/2020/ topicsobjectives2020/overview.aspx?topicid $=29]$

30. WHO. Oral Health Surveys. Basic Methods. 5th Ed,2013. http://www.icd.org/ content/publications/WHO-Oral-Health-Surveys-Basic-Methods-5th-Edition2013.pdf. 
31. Elías-Boneta AR, Crespo Kebler K, Gierbolini CC, Toro Vizcarrondo CE, Psoter WJ. Dental caries prevalence of twelve year olds in Puerto Rico. Community Dent Health. 2003;20:171-6.

32. Torres R, Santos E, Orraca L, Elias A, Palacios C. Diet quality, social determinants, and weight status in puerto rican children aged 12 years. J Acad Nutr Diet. 2014;114:1230-5.

33. Morales Olivo E. La importancia de la preparación universitaria en estudiantes en desventaja social y económica. Revista Griot. 2012;5(1):18-27.

34. NHANES. Antropometric Procedures Manual 2007-2008 http://www.cdc. gov/nchs/data/nhanes/nhanes_07_08/manual_an.pdf

35. Kuczmarski RJ, Ogden CL, Guo SS, Grummer-Strawn LM, Flegal KM, Mei Z, et al. 2000 CDC Growth Charts for the United States: methods and development. Vital Health Stat. 2002;11:1-190.

36. CDC. About BMl for Children and Teens [http://www.cdc.gov/healthyweight/ assessing/bmi/childrens_bmi/about_childrens_bmi.html]

37. Hosmer DW, Lemeshow S. Applyed Logistic Regression. New York; 1989

38. Ogden $\mathrm{CL}$, Carroll MD, Kit BK, Flegal KM. Prevalence of childhood and adult obesity in the United States, 2011-2012. JAMA. 2014;311:806-14.

39. Fryar CD, Ogden CL. Center for Disease Control and Prevention. NCHS Health E-Stat. Prevalence of Underweight Among Children and Adolescents Aged 2-19 Years: United States, 1963-1965 Through 2007-2010. 2012 http://www.cdc.gov/nchs/data/hestat/underweight_child_07_10/underweight_child_07_10.pdf

40. Ogden CL, Carroll MD, Kit BK, Flegal KM. Prevalence of obesity and trends in body mass index among US children and adolescents, 1999-2010. JAMA. 2012;307:483-90.

41. Neumark-Sztainer D, Wall M, Eisenberg ME, Story M, Hannan PJ. Overweight status and weight control behaviors in adolescents: longitudinal and secular trends from 1999 to 2004. Prev Med (Baltim). 2006;43:52-9.

42. Oza-Frank R, Hade EM, Norton A, Scarpitti H, Conrey EJ. Trends in body mass index among Ohio's third-grade children: 2004-2005 to 2009-2010. J Acad Nutr Diet. 2013;113:440-6.

43. Preston AM, Venegas $H$, Rodríguez CA, Vélez-Rodríguez RM. Assessment of the national school lunch program in a subset of schools in San Juan, Puerto Rico: participants vs. non-participants. P R Health Sci J. 2013;32:25-35.

44. Torres R, Serrano M, Pérez CM, Palacios C. Physical environment, diet quality, and body weight in a group of 12-year-old children from four public schools in Puerto Rico. P R Health Sci J. 2014;33:14-21.

45. Serrano M, Torres R, Pérez CM, Palacios C. Social environment factors, diet quality, and body weight in 12-year-old children from four public schools in Puerto Rico. P R Health Sci J. 2014;33:80-7.

46. Dunton GF, Kaplan J, Wolch J, Jerrett M, Reynolds KD. Physica environmental correlates of childhood obesity: a systematic review. Obes Rev. 2009;10:393-402.

47. Ding D, Sallis JF, Norman GJ, Saelens BE, Harris SK, Kerr J, et al. Community food environment, home food environment, and fruit and vegetable intake of children and adolescents. J Nutr Educ Behav, 44:634-8.

48. Briefel RR, Crepinsek MK, Cabili C, Wilson A, Gleason PM. School food environments and practices affect dietary behaviors of US public school children. J Am Diet Assoc. 2009;109(2 Suppl):S91-107.

49. U.S. Census Bureau. Poverty 2010 and 2011. http://www.census.gov/prod/ 2012pubs/acsbr11-01.pdf

50. Ho GYF, Qian H, Kim MY, Melnik TA, Tucker KL, Jimenez-Velazquez IZ, et al. Health disparities between island and mainland Puerto Ricans. Rev Panam Salud Publica. 2006;19:331-9.

51. Wang YC, Orleans CT, Gortmaker SL. Reaching the healthy people goals for reducing childhood obesity: closing the energy gap. Am J Prev Med. 2012:42:437-44.

\section{Submit your next manuscript to BioMed Central and take full advantage of:}

- Convenient online submission

- Thorough peer review

- No space constraints or color figure charges

- Immediate publication on acceptance

- Inclusion in PubMed, CAS, Scopus and Google Scholar

- Research which is freely available for redistribution

Submit your manuscript at www.biomedcentral.com/submit 